\section{PROF. MOEBIUS ON THE EOZÖON} QUESTION

THE eminent zoologist, Dr. Karl Moebius, of Kiel, 1 has recently published a treatise, "Der Bau des Eczöon canadense nach eigenen Untersuchungen ver- glichen mit der Bau der Foraminiferen" "The Structure of Eozöon canadense, according to my own Investigations, compared with the Structure of Foraminifera "), which first appeared in the "Palæontographica" (vol. xxv.), and was afterwards republished separately. Prof. Moebius in clines entirely towards the view of King and Rowney

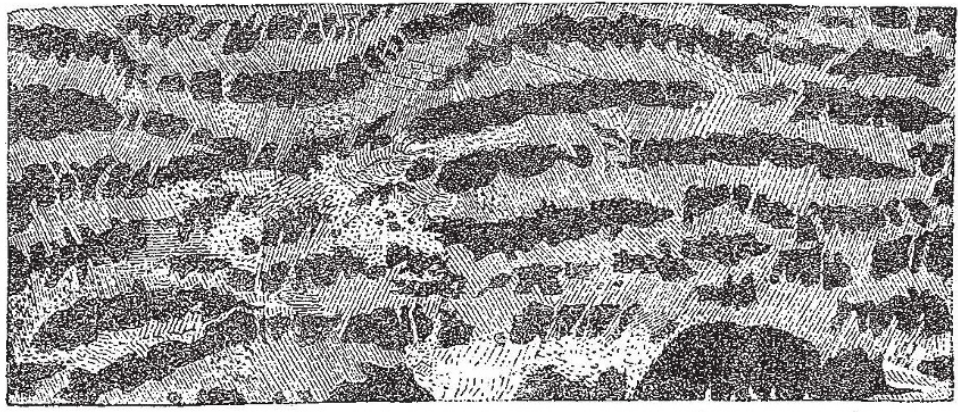

I IG. 1 .

(Proc. Roy. Irish Acad., ser. I, x. and ser. 2, i.) disputing the organic character of Eozöon. The question is one of such great interest, and the paper is so sure to originate controversy, that we have no doubt the following abstract of the chief points in Dr. Moebius's treatise will be welcomed by our readers.
After a concise account of the history of the Eozöon question, since the remarkable discovery by Prof. Dawson and the detailed investigations made by Prof. Carpenter, Dr. Moebius commences the discussion of the subject by stating that he was first led to the study. of Eozöon through observation of the structure ${ }_{n}$ of a

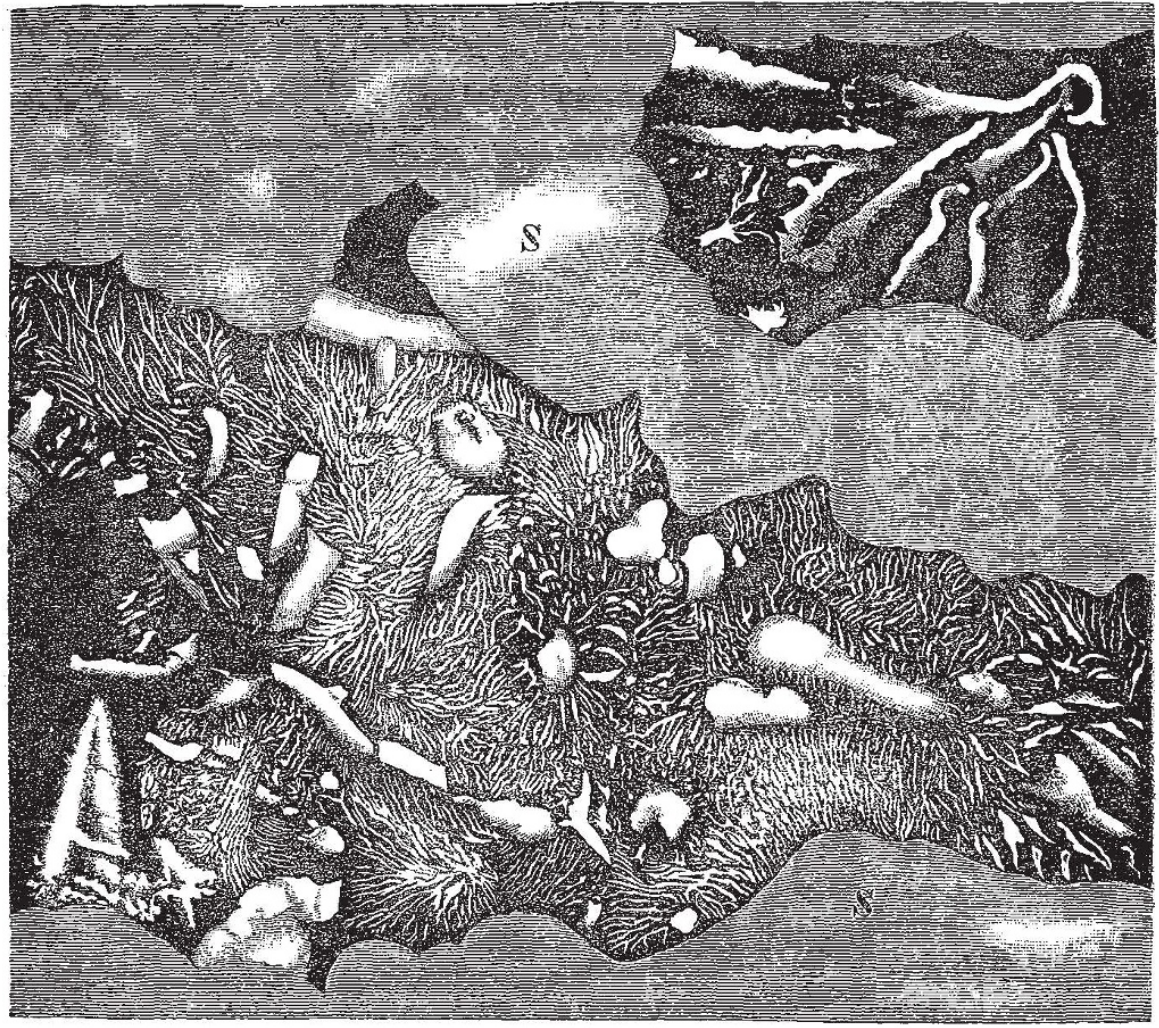

FIG. 2.

rhizopod, found by him in 1874 on the coral reefs near ness to the representations of Eozöon sections accomMauritius, and to which he had given the name of Carpenteria rhaphidodendron. This consists of tree-shaped individuals which often form turf-like growths of several centimetres in length, breadth, and height. Sections of such growths surprised Dr. Moebius by their great likepanying the descriptions published by Dawson, Gümbel Fritsch, \&c. He therefore resolved to make a careful investigation of Eozöon and to compare it with Carpen teria rhaphidodendron and other foraminifera, in order to form his own judgment regarding its nature, and to 
establish such reasons and facts as might leadr: to a generally acceptable and final decision of the Eozöon question.

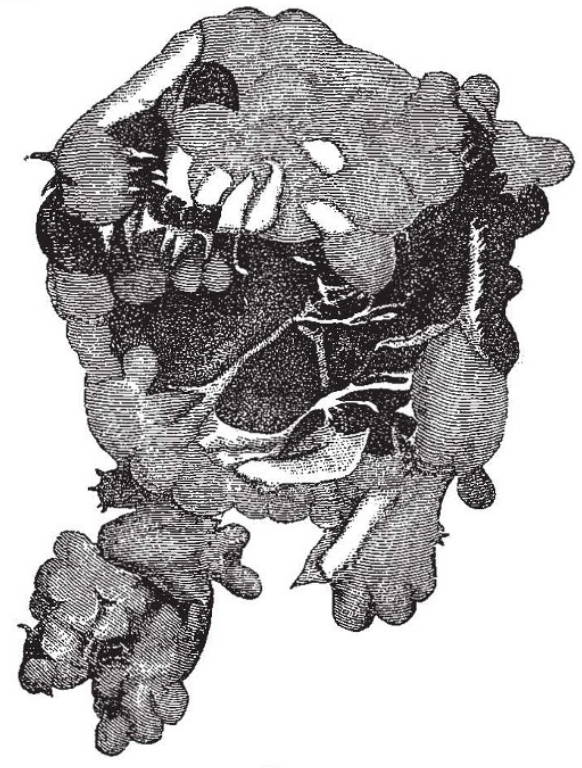

Fig. 3.

With this object in view Dr.Moebius investigated upwards of ninety Eozöon sections, of which many were placed at his disposal through the kindness of Dr. Carpenter, and of which many others originally belonged to Prof. Dawson; there was no doubt, therefore, that the sections possessed those properties which had. led the latter to declare the formation to be of animal origin. According to Dr. Moebius Eozöon canadense consists principally of alternate layers of yellowish green serpentine and whitish limestone. Fig. I is the representation of a good Eozöon section, magnified four times.

The darker parts represent the serpentine, the lighter ones the limestone which in many places completely surrounds little rounded nodules of serpentine. Both the limestone layers, as well as the serpentine layers, have indentures and frequently end in wedge-shaped points. They generally attain a thickness of two or three millimetres. In the limestone, even when magnified only four times, the straight and parallel division lines of the thin layers of which it is composed are easily seen. Besides these division lines groups of little dots or of curved lines are noticed, representing stems and thin plates imbedded in it. These stem- and plate-shaped formations, which are of great importance with regard to the introduction of Eozöon amongst foraminifera, will be better recognised in Fig. 2.
This represents a small part of an Eozöon section, from which the limestone has been dissolved by hydrochloric acid, magnified forty times, under reflected light. The acid has only left the serpentine and the stems and plates, which, like serpentine, consist principally of silica

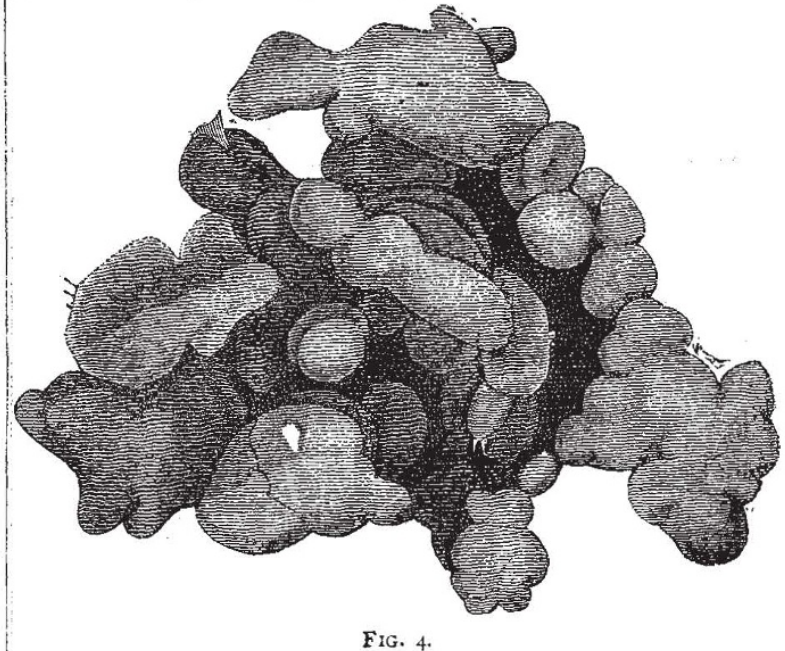

and magnesia. Between the indented bands of serpentine (S S) we see cavities which were formerly filled up by carbonate of lime. From the bottom of these cavities, which also consists of serpentine, stems and plates of

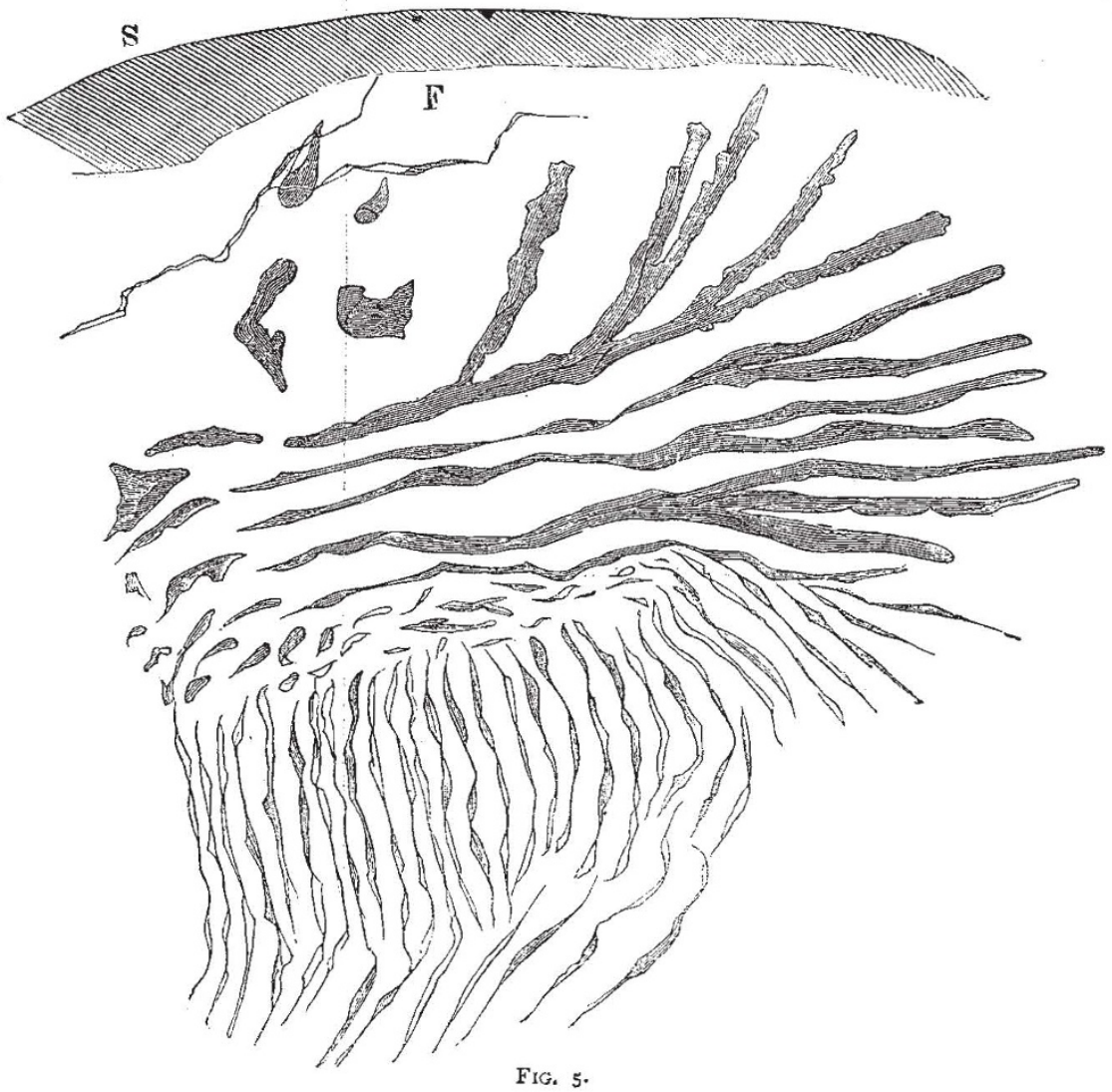

FrG. 5.

different shape and size rise in different directions. Many parts of the Eozöon contain a much smaller number 
of stems than are shown in Fig. 2, such as the piece $/$ which is also magnified forty times. Still poorer in stems represented in Fig. 3, where the lime is also removed, and is Fig. 4, where only a few nodules of serpentine are pro-

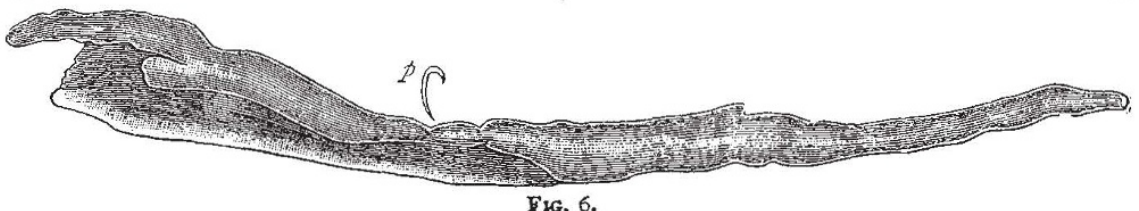

vided with stems. Figs. 3 and 4 may at the same time by yet more powerful microscopes and under transmitted

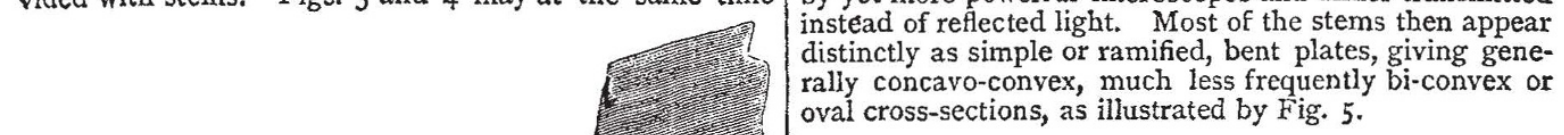
oval cross-sections, as illustrated by Fig. 5 .

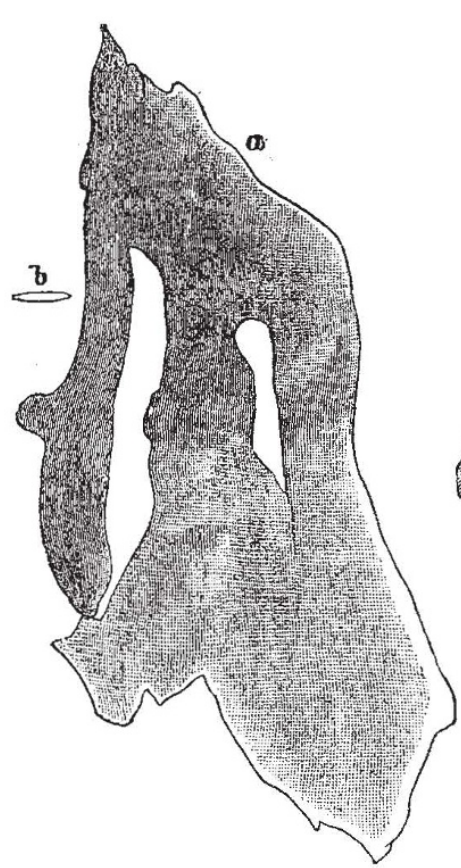

FiG. 7.

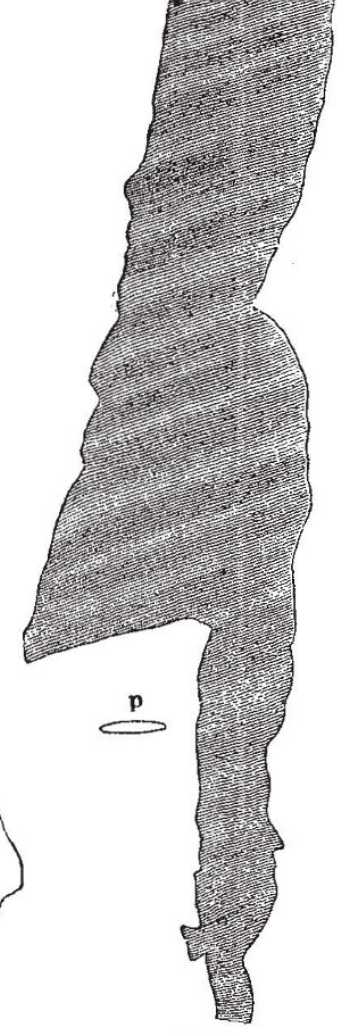

FIG. 8.

serve to illustrate certain round shapes in the serpentine of Eozöon and their almost spiral arrangement.

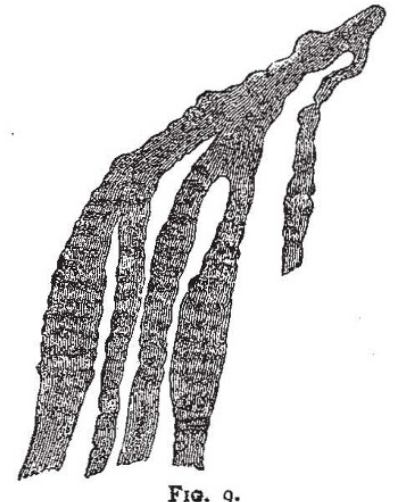

Fre. 9.

If Eozöon sections are cut and ground to such thinness that they become translucent, then they may be examined

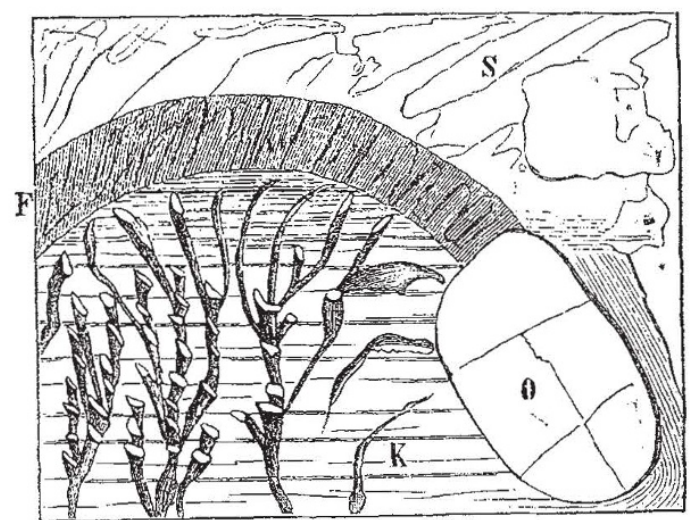

FIG. 10.

This figure represents stems magnified 150 times. A the margin of the lime in which the stems are imbedded bands of fine fibres are seen; we shall refer to these and their significance with regard to the introduction of Eozöon amongst foraminifera. Perfect certainty

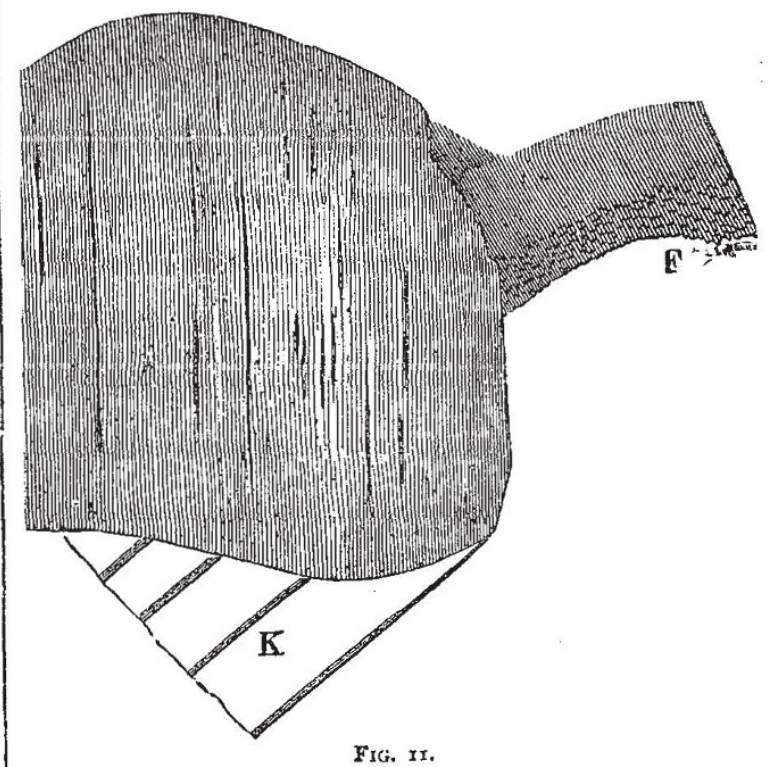

as to the shape of stems and plates was arrived at by treating the thin sections containing such inclosures with dilute hydrochloric acid until the stems were laid completely bare. Thus they could be separately and closely examined in a drop of water under the microscope, and a clear and exact notion of their shape could be obtained. 
Figs. 6 to 9 represent several stems and plates isolated in the manner described and magnified 350 times.

Fig. 6 shows a bent and half tube-shaped stem; Fig. 7 a plate with two apertures; Fig. 8 a plate with alternate and parallel thicker and thinner parts; Fig. 9 a ramified stem of similar structure. In Fig. 6 the shape of the cross-section is indicated. The alternately thinner and thicker parts in Figs. 8 and 9 correspond to the lamellæ of the lime in which they laid imbedded, and therefore probably have their origin from these.

Now we have only to consider the fibres, which in many parts of the Eozöon, at the borders of the calcareous parts carrying the stems, surround the serpentine-like bands, but which in other parts pass right through the serpentine. In Fig. 5 these fibres are marked $F$, while the serpentine is designated by $S$. A very well-defined band of fibres is seen in Fig. Io (magnified 200 times), between the serpentine $S$ and a piece of lime in which obliquely ascending stems are cut right across at the surface of the section. $O$ is a crystal of olivine in course of decomposition, and therefore no longer possessing sharp edges.

The fibres are imperfectly developed micro-crystals of chrysotile, which like olivine and serpentine consists of silica and magnesia. In many fibre-bands, with the application of strong magnifying powers, it is observed that the fibres are very small four-sided prisms. In Fig. II, near F, such fibres are shown, magnified 500 times; to the left are long, less distinct, needle-shaped chrysotile crystals, besides lime $(\mathrm{K})$.

(To be continued.)

\section{NOTES}

WE have received from the U.S. Signal Office the monthly Bulletins for November and December, 1874, January, 1875, and January, February, and March, 1877. We hope shortly to begin, through the courtesy of General Myer, the regular publication of a map exhibiting the simultaneous monthly means in meteorology of the whole of the Northern Hemisphere. The immense value of such a publication to meteorological science we need not point out, and the enterprise of the U.S. Signal Office in working out and making public these data is beyond praise.

THE Astronomical Museum established by Admiral Mouchez in the Paris Observatory may be considered as now complete. Besides the pictures of the principal celestial objects and portraits of the directors of the Paris Observatory, the hall contains a number of objects connected with astrology as well as astronomy, and a number of historical instruments, as the bar which was used for measuring the Peruvian degree, the similar instrument which was taken to Lapland by the Northern Commission; the pendulum used by Duperrey, and that used by Fraissinet for measuring the intensity of gravity in remote lands, the former being constructed by Fresnel ; the bi-refracting prism used by Arago for his great optical discoveries, the portable meridian circle designed by Admiral Mouchez, \&c., \&c.

A solution of a problem which has lately acquired some celebrity, viz., How to colour a map with four colours without colouring adjacent districts the same colour, has just been obtained by Mr. A. B. Kempe, and will shortly appear at length in the American Foumal of Mathenatics. The fact that a map could be so coloured was stated by Prof. De Morgan to be well-known to map-makers, but no proof of the fact or means of solving the problem have hitherto, it is believed, been given. Some notion of the difficulty involved may be gathered from the fact that a very slight alteration in a map may render it necessary to recølour it thronghout. Mr. Kempe's solution may be roughly described as follows:- $-\mathrm{He}$ points out that every map must have a district in it with less than six surrounding it. This district he gets rid of by putting a patch over it which just projects over its boun- daries, all boundaries which meet the patch being produced to meet in a point on the patch. A new map is thus obtained having one district less. This map must also have a district with less than six surrounding it which can be patched out in the same way. Continuing this process the map can at last be reduced to a blank sheet composed of overlapping patches. This can be coloured with a single colour. Stripping off the patches in the reverse order and colouring the districts as they are exposed, Mr. Kempe shows that whenever the $\mathrm{I}, 2,3,4$, or 5 districts surrounding a newly exposed one absorb all four colours, the colours can be rearranged in the map so as to reduce the surrounding colours to three, thus leaving a fourth for the exposed district. Thus successively taking off patches, rearranging the colours in the map, if necessary, a.t colouring the exposed districts, the whole map can be coloured. Mr. Kempe also shows inter alia that while the theorem is true in the case of globular surfaces as well as in that of maps, it does not hold in the case of such a surface as an anchor-ring.

WE have received a copy of the second part of Mr. W. B. Hemsley's "Diagnoses Plantarum Novarum Mexicanarum et Centrali-Americanarum." We believe that the whole of the MSS. of the Polypetalce of the botany of Messrs. Godman and Salvin's "Biologia Centrali-Americana," is now in the hands of the printer, and Mr. Hemsley is far advanced with the Gamopetalce. The first part of the Polypetalæe will shortly appear. The publication of the Polypetalæ has been delayed, in order to include a very valuable collection made last year in the State of San Luis Potosi, Mexico, by Drs. Parry and Palmer.

A SERIES of interesting experiments with the electric light commenced, by order of the authorities, at the School of Military Engineering, Chatham, on Thursday last. The experiments are for testing the relative qualities of the several inventions now in use in the Army and Navy, including Messrs. Wylde's invention (which has been fitted on board nearly all the larger ironclads in the Navy), Messrs. Siemens' invention, the Gramme light, and others. The experiments, it is expected, will last several weeks, and they will be carried out under the direction of Capt. Arm. strong, R.E., instructor in telegraphy at the School of Military Engineering.

THE Council of the Institution of Civil Engineers have recently made their annual awards, out of special funds bequeathed for the purpose, for approved original communications read and dis. cussed at the weekly meetings during the past session, or printed in the "Minutes of Proceedings" without being read, as well as for papers submitted by students. From the Telford Fund medals and premiums have been bestowed on Messrs. G. F. Deacon, J. B. Mackenzie, J. N. Douglass, A. F. Blandy, E. Dobson, J. Price, J. E. Williams, G. W. Sutcliffe, E. Sang, W. G. Laws, and G. Higgin. The Manby Premium has fallen to Mr. J. P. Griffith. Miller Prizes have been adjudged to the following students :-Messrs. A. C. Hurtzig, R. H. Read, J. C. Mackay, and P. W. Britton.

THE fourth marine excursion of the Birmingham Natura ${ }^{1}$ History and Microscopical Society to Falmouth, which extended. from July 5 to 14 , has proved a great success; and quite equalled, if not surpassed, the preceding ones to Teignmouth and the Island of Arran. A larger number of members than usual joined the party, which consisted of nine ladies and twenty-two gentlemen-a total of thirty-one. As hitherto the excursion was arranged so as to give facilities for the study of the marine zoology, botany, and geology of the district. For the former of these an admirable little steam tug, the Albert, was engaged. Land excursions were also arranged daily to interesting points, including the Land's End, the Lizard, \&c. For the first time 